\title{
TEOREMA TITIK TETAP PADA RUANG METRIK CONE
}

\author{
ZAINUL RAHMAT, HARIPAMYU, SHELVI EKARIANI \\ Program Studi S1 Matematika, \\ Fakultas Matematika dan Ilmu Pengetahuan Alam, Universitas Andalas, \\ Kampus UNAND Limau Manis Padang, Indonesia. \\ email:zainulrahmat23@gmail.com,haripamyu@sci.unand.ac.id,shelviekariani@sci.unand.ac.id
}

\begin{abstract}
Abstrak. Ruang metrik cone merupakan suatu himpunan tak kosong $X$ yang dilengkapi oleh pemetaan $d$ dari $X \times X$ ke ruang Banach dan memenuhi beberapa aksioma. Selanjutnya didefinisikan titik tetap $x \in X$ dari suatu pemetaan $T$. Dengan memanfaatkan konsep kekonvergenan barisan pada ruang metrik cone, diperoleh bahwa pemetaan kontraktif pada ruang metrik cone lengkap memiliki titik tetap tunggal.
\end{abstract}

Kata Kunci: Konvergen, Ruang Metrik, Ruang Metrik Cone dan Titik Tetap

\section{Pendahuluan}

Analisis fungsional merupakan salah satu cabang dari matematika analisis klasik. Pada analisis fungsional dibahas mengenai "ruang" yang disertai dengan "fungsi" yang terdefinisi pada ruang tersebut. Sebagai contoh, ruang vektor yang disertai "fungsi norm" dinamakan sebagai "ruang norm". Selanjutnya himpunan tak kosong yang disertai "fungsi jarak" dinamakan sebagai "ruang metrik".

Fungsi jarak pada ruang metrik merupakan fungsi bernilai riil [4]. Pada ruang metrik berlaku konsep kekonvergenan barisan. Salah satu teorema yang memanfaatkan konsep kekonvergenan pada ruang metrik adalah teorema titik tetap Banach.

Teorema titik tetap Banach menjadi landasan dari teorema eksistensi dan ketunggalan dalam matematika analisis. Bentuk perluasan dari ruang metrik adalah ruang metrik cone, dimana fungsi jarak pada ruang metrik cone merupakan suatu pemetaan menuju ruang banach. Pada ruang metrik cone juga terdapat konsep kekonvergenan barisan seperti pada ruang metrik sehingga teorema titik tetap juga dapat diterapkan pada ruang metrik cone.

Dalam artikel ini akan dikaji kembali tentang konsep kekonvergenan pada ruang metrik cone dan menganalisis keberadaan dan ketunggalan titik tetap pada ruang metrik cone dengan merujuk artikel dari Huang Long-Guang dan Zhang Xhian [5].

${ }^{*}$ Penulis Korespondensi 


\section{Landasan Teori}

\subsection{Ruang Banach}

Definisi 2.1. [4] Misalkan X suatu ruang vektor. Norm pada X adalah suatu fungsi bernilai riil yang dinotasikan oleh $\|\cdot\|$ sedemikian sehingga untuk setiap $x, y \in X$ dan $\alpha$ konstan berlaku :

(1) $\|x\| \geq 0$;

(2) $\|x\|=0 \Leftrightarrow x=\overline{0}$;

(3) $\|\alpha x\|=|\alpha|\|x\| ;$ dan

(4) $\|x+y\| \leq\|x\|+\|y\|$.

Pasangan terurut $(X,\|\cdot\|)$ disebut ruang norm.

Dalam tulisan ini, ruang norm $(X,\|\cdot\|)$ dinotasikan dengan $X$.

Contoh 2.2. Misalkan $X=\mathbb{R}^{n}$ adalah suatu ruang vektor, didefinisikan suatu norm $\|x\|=\sum_{i=1}^{n}\left(\left|x_{i}\right|\right)$. Maka $\mathbb{R}^{n}$ adalah ruang norm.

Bukti. Ambil sebarang $\alpha \in \mathbb{R}$ dan $x, y \in \mathbb{R}^{n}$ dimana $x=\left(x_{1}, x_{2}, x_{3}, \cdots, x_{n}\right)$ dan $y=\left(y_{1}, y_{2}, y_{3}, \cdots, y_{n}\right)$.

(1) Karena $\left|x_{i}\right| \geq 0$ untuk setiap $i=1,2,3, \cdots, n$. Maka $\|x\|=\sum_{i=1}^{n}\left|x_{i}\right| \geq 0$. Terbukti $\|x\| \geq 0$.

(2) Akan ditunjukkan $\|x\|=0 \Leftrightarrow x=\overline{0}$.

$(\Rightarrow)$ Misalkan $\|x\|=0$, akan ditunjukkan $x=\overline{0}$.

Untuk sebarang $x_{i} \in \mathbb{R},\left|x_{i}\right|=0$ jika dan hanya jika $x_{i}=0$. Andaikan terdapat $x_{i} \neq 0$, akibatnya $\|x\|=\sum_{i=1}^{n}\left|x_{i}\right|>0$. Maka haruslah $x_{i}=0$ untuk setiap $i=1,2,3, \cdots, n$ atau dengan kata lain $x=\overline{0}$.

$(\Leftarrow)$ Misalkan $x=\overline{0}$, akan ditunjukkan $\|x\|=0$.

Karena $x=\overline{0}$, maka $x_{i}=0$ untuk setiap $i=1,2,3, \cdots, n$. Akibatnya $\|x\|=\sum_{i=1}^{n}\left(\left|x_{i}\right|\right)=0$.

Terbukti $\|x\|=0 \Leftrightarrow x=\overline{0}$.

(3) Akan ditunjukkan $\|\alpha x\|=|\alpha|\|x\|$.

$$
\begin{aligned}
\|\alpha x\| & =\sum_{i=1}^{n}\left|\alpha x_{i}\right| \\
& =\left|\alpha x_{1}\right|+\left|\alpha x_{2}\right|+\left|\alpha x_{3}\right|+\cdots\left|\alpha x_{n}\right| \\
& =|\alpha|\left|x_{1}\right|+|\alpha|\left|x_{2}\right|+|\alpha|\left|x_{3}\right|+\cdots+|\alpha|\left|x_{n}\right| \\
& =|\alpha|\|x\|
\end{aligned}
$$


(4) Akan ditunjukkan $\|x+y\| \leq\|x\|+\|y\|$.

$$
\begin{aligned}
\|x+y\| & =\sum_{i=1}^{n}\left|x_{i}+y_{i}\right| \\
& =\left|x_{1}+y_{1}\right|+\left|x_{2}+y_{2}\right|+\left|x_{3}+y_{3}\right|+\cdots+\left|x_{n}+y_{n}\right| \\
& \leq\left|x_{1}\right|+\left|y_{1}\right|+\left|x_{2}\right|+\left|y_{2}\right|+\left|x_{3}\right|+\left|y_{3}\right|+\cdots+\left|x_{n}\right|+\left|y_{n}\right| \\
& =\left|x_{1}\right|+\left|x_{2}\right|+\left|x_{3}\right|+\cdots+\left|x_{n}\right|+\left|y_{1}\right|+\left|y_{2}\right|+\left|y_{3}\right|+\cdots+\left|y_{n}\right| \\
& =\|x\|+\|y\| .
\end{aligned}
$$

Terbukti bahwa $\mathbb{R}^{n}$ ruang norm.

Berikut diberikan definisi kekonvergenan barisan pada ruang norm.

Definisi 2.3. [4] Misalkan $\left(x^{(n)}\right)$ suatu barisan pada ruang norm X. Barisan $\left(x^{(n)}\right)$ dikatakan konvergen ke $x \in X$ jika $\lim _{n \rightarrow \infty}\left\|x^{(n)}-x\right\|=0$, kemudian dinotasikan dengan $\left\|x^{(n)}-x\right\| \rightarrow 0$.

Definisi 2.4. [4] Suatu barisan $\left(x^{(n)}\right)$ pada ruang norm $X$ disebut barisan Cauchy jika untuk setiap $\epsilon>0$ terdapat $N_{(\epsilon)} \in \mathbb{N}$ sedemikian sehingga untuk setiap $m, n \in \mathbb{N}$ dengan $m, n>N_{(\epsilon)}$ berlaku $\left\|x^{(n)}-x^{(m)}\right\|<\epsilon$.

Pada tulisan ini digunakan kriteria kekonvergenan Cauchy pada bilangan riil.

Lema 2.5. [1] Kriteria Kekonvergenan Cauchy: Barisan bilangan riil dikatakan konvergen jika dan hanya jika barisan tersebut merupakan barisan Cauchy.

Definisi 2.6. [4] Suatu ruang norm $X$ dikatakan lengkap jika setiap barisan Cauchy pada ruang norm tersebut konvergen pada $X$. Ruang norm lengkap disebut ruang Banach.

Contoh 2.7. Ruang norm pada Contoh 2.2 merupakan ruang Banach.

Bukti. Misalkan $\left(x^{(m)}\right)$ sebarang barisan Cauchy pada ruang norm $\mathbb{R}^{n}$ dimana $\left(x^{(m)}\right)=\left(x_{1}^{(m)}, x_{2}^{(m)}, x_{3}^{(m)}, \cdots, x_{n}^{(m)}\right)$. Karena $\left(x^{(n)}\right)$ merupakan barisan Cauchy, untuk setiap $\epsilon>0$ terdapat $N_{(\epsilon)} \in \mathbb{N}$ sedemikian hingga untuk setiap $k, l \in \mathbb{N}$ dimana $k, l>N_{(\epsilon)}$ berlaku:

$$
\left\|x^{(k)}-x^{(l)}\right\|=\sum_{i=1}^{n}\left|x_{i}^{(k)}-x_{i}^{(l)}\right|<\epsilon
$$

Akibatnya untuk setiap $i=1,2,3, \cdots, n$ berlaku:

$$
\left|x_{i}^{(k)}-x_{i}^{(l)}\right|<\epsilon .
$$

Maka untuk sebarang $i$, barisan $\left(x_{i}^{(1)}, x_{i}^{(2)}, x_{i}^{(3)}, \cdots\right)$ merupakan barisan Cauchy di $\mathbb{R}$. Berdasarkan Kriteria Kekonvergenan Cauchy, barisan $\left(x_{i}^{(1)}, x_{i}^{(2)}, x_{i}^{(3)}, \cdots\right)$ konvergen ke suatu $x_{i} \in \mathbb{R}$. Karena $i$ sebarang, maka $x^{(m)}$ konvergen ke suatu $x \in \mathbb{R}^{n}$. Karena $\left(x^{(m)}\right)$ sebarang barisan Cauchy di $\mathbb{R}^{n}$, maka $\mathbb{R}^{n}$ merupakan ruang norm lengkap. 


\subsection{Cone}

Pada subbab ini akan dijelaskan mengenai lingkungan, himpunan terbuka dan himpunan tertutup.

Definisi 2.8. [6] Misalkan $X$ suatu ruang norm, $a \in X$ dan $\epsilon>0$. Lingkungan- $\epsilon$ dari a didefinisikan oleh $V_{(\epsilon)}(a)=\{x \in X ;\|x-a\|<\epsilon\}$.

Definisi 2.9. [4] Misalkan $X$ ruang norm, $P \subset X$ dan $p \in P$. Titik $p$ merupakan titik interior di $P$ jika terdapat $\epsilon>0$ sedemikian sehingga $V_{(\epsilon)}(p) \subset P$. Himpunan titik interior $P$ dinotasikan sebagai $P^{\circ}$.

Definisi 2.10. [6] Misalkan $X$ suatu ruang norm dan $P \subset X$. Himpunan $P$ dikatakan terbuka jika untuk setiap $p \in P$ berlaku $p \in P^{\circ}$.

Definisi 2.11. [6] Misalkan $X$ suatu ruang norm dan $P \subset X$. Himpunan $P$ dikatakan tertutup jika himpunan $P$ komplemen $\left(P^{c}\right)$ terbuka.

Contoh 2.12. Misalkan ruang norm $\mathbb{R}^{2}$ dengan norm yang didefinsikan oleh $\|x\|=\left|x_{1}\right|+\left|x_{2}\right|$ dan $P=\left\{\left(x_{1}, x_{2}\right) ; x_{1}, x_{2} \geq 0\right\}$. Himpunan $P$ adalah himpunan tertutup.

Bukti. Akan ditunjukkan $P^{c}=\mathbb{R}^{2}-P$ merupakan himpunan terbuka. Perhatikan bahwa $P^{c}=\left\{\left(x_{1}, x_{2}\right) ; x_{1}<0\right.$ atau $\left.x_{2}<0\right\}$. Ambil sebarang $p=\left(p_{1}, p_{2}\right) \in P^{c}$ akan ditunjukkan bahwa $p \in\left(P^{c}\right)^{\circ}$.

(1) Kasus $1: p_{1}<0$.

Pilih $\epsilon=-\frac{p_{1}}{2}$. Akibatnya $V_{\left(-\frac{p_{1}}{2}\right)}(p) \subset P^{c}$, dengan kata lain $p \in\left(P^{c}\right)^{\circ}$.

(2) Kasus $2: p_{2}<0$

Pilih $\epsilon=-\frac{p_{2}}{2}$. Akibatnya $V_{\left(-\frac{p_{2}}{2}\right)}(p) \subset P^{c}$, dengan kata lain $p \in\left(P^{c}\right)^{\circ}$.

Terbukti $P^{c}$ himpunan terbuka.

Selanjutnya akan diberikan definisi dari cone.

Definisi 2.13. [5] Misalkan $P \subset E$ dan $E$ adalah ruang Banach. $P$ dikatakan cone jika dan hanya jika memenuhi kondisi berikut:

(1) Himpunan $P$ bukan himpunan kosong, dan $P \neq\{\overline{0}\}$.

(2) Himpunan $P$ merupakan himpunan tertutup.

(3) Untuk setiap $a, b \in \mathbb{R}$ dan $a, b \geq 0$, jika $x, y \in P$ maka $a x+b y \in P$.

(4) Jika $x \in P$ dan $-x \in P$ maka $x=\overline{0}$.

Contoh 2.14. Diberikan ruang Banach $\mathbb{R}^{2}$. Kemudian didefinisikan $P$ dimana $P=\left\{\left(x_{1}, x_{2}\right) ; x_{1}, x_{2} \geq 0\right\}$. Himpunan $P$ merupakan cone.

Bukti. Ambil sebarang $x, y \in \mathbb{R}^{2}$. Misal $x=\left(x_{1}, x_{2}\right), y=\left(y_{1}, y_{2}\right)$ dimana $x_{1}, x_{2}, y_{1}, y_{2} \geq 0$

(1) Karena $x_{1}, x_{2}, y_{1}, y_{2} \geq 0$, maka $x, y \in P$. Akibatnya $P \neq \emptyset$, dan $P \neq\{\overline{0}\}$.

(2) Berdasarkan Contoh 2.12 terbukti $P$ tertutup. 
(3) Untuk setiap $a, b>0$ berlaku $a x_{1}+b y_{1} \geq 0$ dan $a x_{2}+b y_{2} \geq 0$. Maka $a x+b y \in P$.

(4) Misalkan $x \in P$ dan $x \neq \overline{0}$. Maka $x_{1}>0$ atau $x_{2}>0$. Akibatnya $-x_{1}<0$ atau $-x_{2}<0$. Perhatikan bahwa $-x=\left(-x_{1},-x_{2}\right)$. Karena $-x_{1}<0$ atau $-x_{2}<0$, maka $-x \notin P$. Agar $x \in P$ dan $-x \in P$ haruslah $x=\overline{0}$.

Terbukti $P$ merupakan cone.

Pada suatu cone $P$, didefinisikan notasi urutan yang berkenaan dengan cone $P$. Notasi tersebut diberikan pada definisi berikut ini.

Definisi 2.15. [2] Misalkan $E$ ruang Banach, $P \subseteq E$, dan $P$ suatu cone. Untuk setiap $x, y \in E$ didefinisikan urutan parsial sebagai berikut :

(1) $x \preceq y \Leftrightarrow y-x \in P$;

(2) $x \prec y \Leftrightarrow y-x \in P$, tetapi $x \neq y$;

(3) $x \ll y \Leftrightarrow y-x \in P^{\circ}$.;

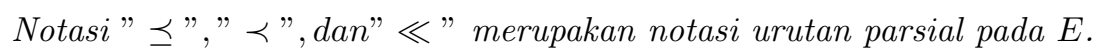

Definisi 2.16. [5] Cone $P$ disebut normal jika terdapat $K>0$ sedemikian sehingga untuk setiap $x, y \in E$, berlaku

$$
\overline{0} \preceq x \preceq y \Rightarrow\|x\| \leq K\|y\| .
$$

\subsection{Ruang Metrik Cone}

Definisi 2.17. [7] Misalkan E ruang Banach dan $X$ himpunan tak kosong. Didefinisikan pemetaan $d: X \times X \rightarrow E$ sedemikian sehingga untuk setiap $x, y, z \in X$ berlaku:

(1) $\overline{0} \preceq d(x, y)$;

(2) $d(x, y)=\overline{0} \Leftrightarrow x=y$;

(3) $d(x, y)=d(y, x)$; dan

(4) $d(x, y) \preceq d(x, z)+d(z, y)$.

Pemetaan d disebut metrik cone pada $X$ dan $(X, d)$ disebut ruang metrik cone.

Contoh 2.18. Diberikan ruang Banach $\mathbb{R}^{2}, P=\left\{\left(x_{1}, x_{2}\right) ; x_{1}, x_{2} \geq 0\right\}$, dan $d: \mathbb{R}^{2} \times \mathbb{R}^{2} \rightarrow \mathbb{R}^{2}$ didefinisikan oleh $d(x, y)=\left(\left|x_{1}-y_{1}\right|, \alpha\left|x_{2}-y_{2}\right|\right)$ dimana $\alpha_{1}>0$. Maka $\left(\mathbb{R}^{2}, d\right)$ merupakan ruang metrik cone.

Bukti. Ambil sebarang $x, y, z \in \mathbb{R}^{2}$ dimana $x=\left(x_{1}, x_{2}\right), y=\left(y_{1}, y_{2}\right)$, $z=\left(z_{1}, z_{2}\right)$ dan $\alpha>0$ konstanta.

(1) Perhatikan bahwa $d(x, y)-\overline{0}=\left(\left|x_{1}-y_{1}\right|, \alpha\left|x_{2}-y_{2}\right|\right)$. Karena $\left|x_{1}-y_{1}\right| \geq 0$ dan $\alpha\left|x_{2}-y_{2}\right| \geq 0$, maka $d(x, y)-\overline{0} \in P$. Terbukti $\overline{0} \preceq d(x, y)$.

$(2)(\Rightarrow)$ Diketahui $d(x, y)=\overline{0}$. Seandainya $x \neq y$, akibatnya $\left|x_{1}-y_{1}\right|>0$ atau $\alpha\left|x_{2}-y_{2}\right|>0$. Akibatnya $\overline{0} \prec d(x, y)$, sehingga haruslah $x=y$. 
$(\Leftarrow)$ Misalkan $x=y$, Perhatikan bahwa:

$$
\begin{aligned}
d(x, y) & =\left(\left|x_{1}-y_{1}\right|, \alpha\left|x_{2}-y_{2}\right|\right) \\
& =(0, \alpha 0)=\overline{0} .
\end{aligned}
$$

Terbukti $d(x, y)=\overline{0} \Leftrightarrow x=y$.

(3) Perhatikan bahwa:

$$
\begin{aligned}
d(x, y) & =\left(\left|x_{1}-y_{1}\right|, \alpha_{1}\left|x_{2}-y_{2}\right|\right) \\
& =\left(\left|y_{1}-x_{1}\right|, \alpha\left|y_{2}-x_{2}\right|\right) \\
& =d(y, x) .
\end{aligned}
$$

(4) Akan ditunjukkan $d(x, y) \preceq d(x, z)+d(z, y)$.

$$
\begin{aligned}
d(x, y) & =\left(\left|x_{1}-y_{1}\right|, \alpha\left|x_{2}-y_{2}\right|\right) \\
& =\left(\left|x_{1}-z_{1}+z_{1}-y_{1}\right|, \alpha\left|x_{2}-z_{2}+z_{2}-y_{2}\right|\right) \\
& \preceq\left(\left|x_{1}-z_{1}\right|+\left|z_{1}-y_{1}\right|, \alpha\left(\left|x_{2}-z_{2}\right|+\left|z_{2}-y_{2}\right|\right)\right) \\
& =\left(\left|x_{2}-z_{2}\right|, \alpha_{1}\left|x_{2}-z_{2}\right|\right)+\left(\left|z_{1}-y_{1}\right|, \alpha\left|z_{2}-y_{2}\right|\right) \\
& =d(x, z)+d(z, y) .
\end{aligned}
$$

Proposisi 2.19. [7] Misalkan $(X, d)$ ruang metrik cone, sedemikian sehingga untuk setiap $u, v, w \in E$ berlaku:

(1) jika $u \preceq \alpha v$ untuk setiap $\alpha \in[0,1)$, maka $u=\overline{0}$,

(2) jika $\overline{0} \preceq u \ll v$ untuk setiap $\overline{0} \ll v$, maka $u=\overline{0}$,

(3) jika $u \preceq v$ dan $v \ll w$, maka $u \ll w$.

Berikut ini didefinisikan titik tetap suatu pemetaan dan pemetaan kontraktif pada ruang metrik cone.

Definisi 2.20. [4] Misalkan $X$ sebarang himpunan tak kosong dan pemetaan $T: X \rightarrow X$. Suatu $x \in X$ merupakan titik tetap dari pemetaan $T$ jika berlaku $T x=x$.

Definisi 2.21. [4] Didefinisikan metrik cone $(X, d)$ dan pemetaan $T$ : $X \rightarrow X$. Pemetaan $T$ merupakan pemetaan kontraktif pada $X$ jika terdapat $k \in \mathbb{R}$ dimana $0<k<1$ sedemikian sehingga untuk setiap $x, y \in X$ memenuhi :

$$
d(T x, T y) \preceq k d(x, y) .
$$

\section{Teorema Titik Tetap Pada Ruang Metrik Cone}

Pada Bab ini akan dijelaskan beberapa konsep kekonvergenan barisan pada ruang metrik cone dan teorema titik tetap pada ruang metrik cone. 
274 Zainul Rahmat dkk.

\subsection{Kekonvergenan Barisan Pada Ruang Metrik Cone}

Definisi 3.1. [5] Misalkan $(X, d)$ ruang metrik cone. Didefinisikan barisan $\left(x^{(n)}\right)$ pada $X$. Barisan $\left(x^{(n)}\right)$ dikatakan konvergen ke suatu $x \in X$ jika untuk setiap $c \in E$ dimana $\overline{0} \ll$ c terdapat $N_{(c)} \in \mathbb{N}$ sedemikian sehingga untuk setiap $n>N_{(c)}$ berlaku $d\left(x^{(n)}, x\right) \ll c$. Titik $x$ merupakan limit dari $\left(x^{(n)}\right)$ dan dinotasikan dengan:

$$
\lim _{n \rightarrow \infty} x^{(n)}=x \text { atau } x^{(n)} \rightarrow x
$$

Lema 3.2. [5] Misalkan $(X, d)$ ruang metrik cone dan $P$ merupakan cone normal dengan konstanta normal $K$. Selanjutnya didefinisikan barisan $\left(x^{(n)}\right)$ pada $X$. Barisan $\left(x^{(n)}\right)$ dikatakan konvergen ke suatu $x \in X$ jika dan hanya jika $d\left(x^{(n)}, x\right) \rightarrow \overline{0}$ untuk $n, m \rightarrow \infty$.

Bukti. $(\Rightarrow)$ Misalkan $\left(x^{(n)}\right) \rightarrow x$. Akan ditunjukkan $d\left(x^{(n)}, x\right) \rightarrow \overline{0}$.

Ambil sebarang $\epsilon>0$, pilih $c \in E$ dimana $0 \ll c$ dan $K\|c\|<\epsilon$. Karena $\left(x^{(n)}\right)$ konvergen ke $x$, maka terdapat $N_{(c)} \in \mathbb{N}$ sedemikian sehingga untuk setiap $n \in \mathbb{N}$ dengan $n>N_{(c)}$ memenuhi $d\left(x^{(n)}, x\right) \ll c$. Karena $d\left(x^{(n)}, x\right) \ll c$, diperoleh $d\left(x^{(n)}, x\right) \preceq c$. Karena $P$ merupakan cone normal, maka berdasarkan Definisi 2.16 berlaku $\left\|d\left(x^{(n)}, x\right)\right\| \leq K\|c\|$, akibatnya $\left\|d\left(x^{(n)}, x\right)\right\|<\epsilon$. Karena $\epsilon$ sebarang terbukti $d\left(x^{(n)}, x\right) \rightarrow \overline{0}$.

$(\Leftarrow)$ Misalkan $d\left(x^{(n)}, x\right) \rightarrow \overline{0}$. Akan ditunjukkan $\left(x^{(n)}\right) \rightarrow x$.

Ambil sebarang $c \in E$ dimana $\overline{0} \ll c$, pilih $\delta>0$ sedemikian sehingga untuk setiap $x \in E$ dimana $\|x\|<\delta$ berlaku $x \ll c$. Karena $d\left(x^{(n)}, x\right) \rightarrow \overline{0}$, akibatnya $\left\|d\left(x^{(n)}, x\right)\right\| \rightarrow 0$, dengan kata lain terdapat $N_{(\delta)} \in \mathbb{N}$ sedemikian sehingga untuk setiap $n \in \mathbb{N}$ dimana $n>N_{(\delta)}$ berlaku $\left\|d\left(x^{(n)}, x\right)\right\|<\delta$, Sehingga untuk $n$ yang sama berlaku $d\left(x^{(n)}, x\right) \ll c$. Karena $c$ sebarang, terbukti $\left(x^{(n)}\right)$ konvergen ke $x$.

Contoh 3.3. Didefinisikan ruang metrik cone seperti pada Contoh 2.18. Misalkan barisan $\left(x^{(n)}\right)$ di $\mathbb{R}^{2}$ didefinisikan dengan $x^{(n)}=\left(\frac{1}{n}, \frac{\beta}{n}\right)$ dimana $\beta>0$ konstan. Barisan $\left(x^{(n)}\right)$ konvergen ke $x=\overline{0}$.

Bukti. Ambil sebarang $c=\left(c_{1}, c_{2}\right) \in \mathbb{R}^{2}$ dengan $\overline{0} \ll\left(c_{1}, c_{2}\right)$. Pilih $N_{(c)} \in \mathbb{N}$ dimana $N_{(c)}>\sup \left\{\frac{1}{c_{1}}, \frac{\alpha \beta}{c_{2}}\right\}$. Maka untuk setiap $n>N_{(c)}$ berlaku:

$$
\begin{aligned}
d\left(\left(\frac{1}{n}, \frac{\beta}{n}\right),(0,0)\right) & =\left(\frac{1}{n}, \frac{\alpha \beta}{n}\right) \\
& \preceq\left(\frac{1}{N_{(c)}}, \frac{\alpha \beta}{N_{(c)}}\right)
\end{aligned}
$$

Karena $N_{(c)}>\sup \left\{\frac{1}{c_{1}}, \frac{\alpha \beta}{c_{2}}\right\}$, maka $\left(c_{1}-\frac{1}{N_{(c)}}\right)>0 \operatorname{dan}\left(c_{2}-\frac{\alpha \beta}{N_{(c)}}\right)>0$. Akibatnya berlaku $d\left(x^{(n)}, \overline{0}\right) \ll c$. Karena $c$ sebarang, terbukti $\left(x^{(n)}\right)$ konvergen ke $x=\overline{0}$.

Lema 3.4. [5] Misalkan $(X, d)$ suatu metrik cone dan diberikan suatu barisan $\left(x^{(n)}\right)$ konvergen pada $X$. Maka barisan $\left(x^{(n)}\right)$ konvergen ke paling banyak satu $x \in X$. 
Bukti. Ambil sebarang $c \in E$ dengan $\overline{0} \ll c$. Andaikan barisan $\left(x^{(n)}\right)$ konvergen ke $x \in X$ dan $y \in X$, akan ditunjukkan bahwa $x=y$. Karena $\left(x^{(n)}\right)$ konvergen ke $x$ dan $y$, maka berdasarkan Definisi 3.1 terdapat $N_{(c)} \in \mathbb{N}$ sedemikian sehingga untuk setiap $n>N_{(c)}$ berlaku $d\left(x^{(n)}, x\right) \ll \frac{c}{2}$ dan $d\left(x^{(n)}, y\right) \ll \frac{c}{2}$. Karena $d$ merupakan metrik cone, dari Definisi 2.17 diketahui bahwa $d(x, y) \preceq d\left(x^{(n)}, x\right)+d\left(x^{(n)}, y\right)$, akibatnya $d(x, y) \ll c$. Berdasarkan Proposisi 2.19 berlaku $d(x, y) \ll c$. Karena $c$ sebarang, maka berdasarkan Preposisi 2.19 diperoleh $d(x, y)=\overline{0}$. Dari Definisi 2.17 haruslah $x=y$.

Berikut diberikan definisi barisan Cauchy pada ruang metrik cone.

Definisi 3.5. [5] Misalkan ruang metrik cone $(X, d)$, didefinisikan suatu barisan $\left(x^{(n)}\right)$ pada $X$. Jika untuk setiap $c \in E$ dimana $0 \ll c$ terdapat $N_{(c)} \in \mathbb{N}$ sedemikian sehingga untuk setiap $m, n \in \mathbb{N}$ dimana $n, m \geq N_{(c)}$, berlaku $d\left(x^{(n)}, x^{(m)}\right) \ll c$, maka $\left(x^{(n)}\right)$ disebut barisan Cauchy pada X.

Contoh 3.6. Diberikan ruang metrik cone seperti Contoh 2.18. Barisan $\left(x^{(n)}\right)$ yang didefinisikan pada Contoh 3.3 merupakan barisan Cauchy.

Bukti. Ambil sebarang $c=\left(c_{1}, c_{2}\right) \in \mathbb{R}^{2}$ dengan $\overline{0} \ll c$. Pilih $N_{(c)} \in \mathbb{N}$ dimana $N_{(c)}>\sup \left\{\frac{2}{c_{1}}, 2 \frac{\alpha \beta}{c_{2}}\right\}$. Maka untuk setiap $m, n>N_{(c)}$ berlaku :

$$
\begin{aligned}
d\left(\left(\frac{1}{m}, \frac{\beta}{m}\right),\left(\frac{1}{n}, \frac{\beta}{n}\right)\right) & \preceq d\left(\left(\frac{1}{m}, \frac{\beta}{m}\right), \overline{0}\right)+d\left(\left(\frac{1}{n}, \frac{\beta}{n}\right), \overline{0}\right) \\
& =\left(\left|\frac{1}{m}-0\right|, \alpha\left|\frac{\beta}{m}-0\right|\right)+\left(\left|\frac{1}{n}-0\right|, \alpha\left|\frac{\beta}{n}-0\right|\right) \\
& =\left(\frac{1}{m}, \frac{\alpha \beta}{m}\right)+\left(\frac{1}{n}, \frac{\alpha \beta}{n}\right) \\
& \preceq\left(\frac{1}{N_{(c)}}, \frac{\alpha \beta}{N_{(c)}}\right)+\left(\frac{1}{N_{(c)}}, \frac{\alpha \beta}{N_{(c)}}\right) \\
& =\left(\frac{2}{N_{(c)}}, 2 \frac{\alpha \beta}{N_{(c)}}\right) .
\end{aligned}
$$

Karena $N_{(c)}>\sup \left\{\frac{2}{c_{1}}, 2 \frac{\alpha \beta}{c_{2}}\right\}$, maka $\left(c_{1}-\frac{2}{N_{(c)}}\right)>0$ dan $\left(c_{2}-2 \frac{\alpha \beta}{N_{(c)}}\right)>0$. Akibatnya berlaku $d\left(x^{(m)}, x^{(n)}\right) \ll c$. Karena $c$ sebarang, terbukti $\left(x^{(n)}\right)$ barisan Cauchy.

Lema 3.7. [5] Misalkan $(X, d)$ suatu ruang metrik cone dan $\left(x^{(n)}\right)$ suatu barisan pada X. Jika $\left(x^{(n)}\right)$ konvergen ke $x$, maka $\left(x^{(n)}\right)$ adalah barisan Cauchy.

Bukti. Ambil sebarang $c$ dimana $\overline{0} \ll c$. Karena barisan $\left(x^{(n)}\right)$ konvergen, maka terdapat $N_{(c)} \in \mathbb{N}$ sedemikian sehingga untuk setiap $n, m>N_{(c)}$ berlaku $d\left(x^{(n)}, x\right) \ll \frac{c}{2}$ dan $d\left(x^{(m)}, x\right) \ll \frac{c}{2}$. Perhatikan bahwa :

$$
\begin{aligned}
d\left(x^{(n)}, x^{(m)}\right) & \preceq d\left(x^{(n)}, x\right)+d\left(x^{(m)}, x\right) \\
& \ll \frac{c}{2}+\frac{c}{2}=c .
\end{aligned}
$$


Terbukti $\left(x^{(n)}\right)$ Cauchy.

Lema 3.8. [5] Misalkan $(X, d)$ suatu ruang metrik cone dan $P$ merupakan cone normal dengan konstanta normal $K$. Didefinisikan barisan $\left(x^{(n)}\right)$ pada X. Barisan $\left(x^{(n)}\right)$ merupakan barisan Cauchy jika dan hanya jika $d\left(x^{(n)}, x^{(m)}\right) \rightarrow \overline{0}$ untuk $n, m \rightarrow \infty$.

Bukti. $(\Rightarrow)$ Misalkan $\left(x^{(n)}\right)$ adalah barisan Cauchy. Ambil sebarang $\epsilon>0$, pilih $c \in E$ dimana $\overline{0} \ll c$ dan $K\|c\|<\epsilon$. Karena $\left(x^{(n)}\right)$ adalah barisan Cauchy, maka terdapat $N_{(c)} \in \mathbb{N}$ sedemikian sehingga untuk setiap $n, m>N_{(c)}$ berlaku $d\left(x^{(n)}, x^{(m)}\right) \ll c$. Karena $P$ adalah cone normal, maka untuk $n, m>N_{(c)}$ juga berlaku $\left\|d\left(x^{(n)}, x^{(m)}\right)\right\| \leq K\|c\|<\epsilon$. Karena $\epsilon$ sebarang maka $\left\|d\left(x^{(n)}, x^{(m)}\right)\right\| \rightarrow 0$, yang berarti bahwa $d\left(x^{(n)}, x^{(m)}\right) \rightarrow \overline{0}$.

$(\Leftarrow)$ Misalkan $d\left(x^{(n)}, x^{(m)}\right) \rightarrow \overline{0}$. Untuk sebarang $c \in E$ dimana $\overline{0} \ll c$, terdapat $\delta>0$ sedemikian sehingga untuk setiap $y \in E$ dimana $\|y\|<\delta$ berlaku $y \ll c$. Karena $d\left(x^{(n)}, x^{(m)}\right) \rightarrow \overline{0}$, maka untuk $\delta$ yang sama terdapat $N_{(\delta)} \in \mathbb{N}$ sedemikian sehingga untuk setiap $n, m>N_{(\delta)}$ berlaku $\left\|d\left(x^{(n)}, x^{(m)}\right)\right\|<\delta$ sehingga $d\left(x^{(n)}, x^{(m)}\right) \ll c$. Terbukti $\left(x^{(n)}\right)$ adalah barisan Cauchy.

Lema 3.9. [5] Diberikan ruang metrik cone $(X, d)$ dan $P$ merupakan cone normal dengan konstanta normal $K$. Misalkan $\left(x^{(n)}\right)$ dan $\left(y^{(n)}\right)$ merupakan barisan pada $X$ dimana $x^{(n)} \rightarrow x$, dan $y^{(n)} \rightarrow y$ maka $d\left(x^{(n)}, y^{(n)}\right) \rightarrow d(x, y)$ untuk $n, m \rightarrow \infty$.

Bukti. Ambil sebarang $\epsilon>0$, pilih $c \in E$ dimana $\overline{0} \ll c$ dan $\|c\|<\frac{\epsilon}{4 K+2}$. Karena $x^{(n)}$ konvergenke $x$, dan $y^{(n)}$ konvergen ke $y$, maka terdapat $N_{(c)} \in \mathbb{N}$ sehingga untuk setiap $n>N_{(c)}$ berlaku $d\left(x^{(n)}, x\right) \ll c$ dan $d\left(y^{(n)}, y\right) \ll c$. Dengan menggunakan ketaksamaan segitiga diperoleh :

i) $d\left(x^{(n)}, y^{(n)}\right) \preceq d\left(x^{(n)}, x\right)+d(x, y)+d\left(y, y^{(n)}\right) \preceq d(x, y)+2 c$.

ii) $d(x, y) \preceq d\left(x, x^{(n)}\right)+d\left(x^{(n)}, y^{(n)}\right)+d\left(y^{(n)}, y\right) \preceq d\left(x^{(n)}, y^{(n)}\right)+2 c$.

Dari i) dan ii) diperoleh $\overline{0} \preceq d(x, y)+2 c-d\left(x^{(n)}, y^{(n)}\right) \preceq 4 c$. Akibatnya

$$
\begin{aligned}
\left\|d\left(x^{(n)}, y^{(n)}\right)-d(x, y)\right\| & =\left\|d\left(x^{(n)}, y^{(n)}\right)-d(x, y)+2 c-2 c\right\| \\
& \leq\left\|d\left(x^{(n)}, y^{(n)}\right)-d(x, y)+2 c\right\|+\|2 c\| \\
& \leq 4 K\|c\|+2\|c\| \\
& =(4 K+2)\|c\|<\epsilon
\end{aligned}
$$

Terbukti $d\left(x^{(n)}, y^{(n)}\right) \rightarrow d(x, y)$.

Definisi 3.10. [5] Misalkan $(X, d)$ ruang metrik cone, jika setiap barisan Cauchy di $X$ konvergen pada $X$, maka $(X, d)$ disebut ruang metrik cone lengkap.

Contoh 3.11. Ruang metrik cone yang didefinisikan pada Contoh 2.18 merupakan ruang metrik cone lengkap. 
Bukti. Misalkan $\left(x^{(m)}\right)$ sebarang barisan Cauchy pada ruang metrik cone $\left(\mathbb{R}^{2}, d\right)$ dengan $x^{(m)}=\left(x_{1}^{(m)}, x_{2}^{(m)}\right)$. Karena $\left(x^{(m)}\right)$ merupakan barisan Cauchy, maka untuk setiap $c=\left(c_{1}, c_{2}\right) \in \mathbb{R}^{2}$ dengan $\overline{0} \ll c$ terdapat $N_{(c)} \in \mathbb{N}$ sedemikian hingga untuk setiap $k, l \in \mathbb{N}$ dimana $k, l>N_{(c)}$ berlaku

$$
d\left(x^{(k)}, x^{(l)}\right)=\left(\left|x_{1}^{(k)}-x_{1}^{(l)}\right|, \alpha\left|x_{2}^{(k)}-x_{2}^{(l)}\right|\right) \ll c
$$

Akibatnya $\left|x_{1}^{(k)}-x_{1}^{(l)}\right|<c_{1}$ dan $\left|x_{2}^{(k)}-x_{2}^{(l)}\right|<\frac{c_{2}}{\alpha}$. Karena $c$ sebarang, maka barisan $\left(x_{1}^{(1)}, x_{1}^{(2)}, x_{1}^{(3)}, \cdots\right)$ dan $\left(x_{2}^{(1)}, x_{2}^{(2)}, x_{2}^{(3)}, \cdots\right)$ merupakan barisan Cauchy di $\mathbb{R}$. Karena $\left(x_{i}^{(1)}, x_{i}^{(2)}, x_{i}^{(3)}, \cdots\right)$ merupakan barisan Cauchy di $\mathbb{R}$ untuk $i=1,2$ maka $\left(x_{i}^{(1)}, x_{i}^{(2)}, x_{i}^{(3)}, \cdots\right)$ konvergen ke suatu $x_{i} \in \mathbb{R}$. Berdasarkan Kriteria Kekonvergenan Cauchy , maka barisan $\left(x_{1}^{(1)}, x_{1}^{(2)}, x_{1}^{(3)}, \cdots\right)$ konvergen ke suatu $x_{1} \in \mathbb{R}$ dan $\left(x_{2}^{(1)}, x_{2}^{(2)}, x_{2}^{(3)}, \cdots\right)$ konvergen ke suatu $x_{2} \in \mathbb{R}$. Dengan kata lain $\left(x_{1}^{(m)}, x_{2}^{(m)}\right)$ konvergen ke suatu $\left(x_{1}, x_{2}\right) \in \mathbb{R}^{2}$. Karena $\left(x^{(m)}\right)$ sebarang barisan Cauchy di $\mathbb{R}^{2}$ terbukti bahwa $\left(\mathbb{R}^{2}, d\right)$ merupakan ruang norm lengkap.

\subsection{Teorema Titik Tetap Pada Ruang Metrik Cone}

Pada subbab ini akan dibuktikan teorema titik tetap pada ruang metrik cone.

Teorema 3.12. [5] Misalkan $(X, d)$ ruang metrik cone lengkap dan $P$ cone normal dengan konstanta $K$. Didefinisikan pemetaan $T: X \rightarrow X$ yang kontraktif. Maka T memiliki titik tetap tunggal di $X$.

Bukti. Pilih $x^{(0)} \in X$ kemudian definisikan barisan $\left(x^{(n)}\right)$ pada $X$ sebagai berikut:

$$
x^{(1)}=T x^{(0)}, x^{(2)}=T x^{(1)}=T^{2} x^{(0)}, \cdots, x^{(n)}=T x^{(n-1)}=\cdots=T^{n} x^{(0)} .
$$

Karena $T$ kontraktif, maka terdapat $k \in[0,1)$ sedemikian sehingga untuk setiap $n \in \mathbb{N}$ berlaku:

$$
d\left(x^{(n)}, x^{(n+1)}\right) \preceq k d\left(x^{(n-1)}, x^{(n)}\right) \preceq k^{2} d\left(x^{(n-2)}, x^{(n-1)}\right) \preceq \cdots \preceq k^{n} d\left(x^{(0)}, x^{(1)}\right) .
$$

Karena $(X, d)$ ruang metrik cone, berdasarkan Definisi 2.17 untuk setiap $m, n \in \mathbb{N}$ dengan $n>m$ berlaku:

$$
\begin{aligned}
d\left(x^{(m)}, x^{(n)}\right) & \preceq d\left(x^{(m)}, x^{(m+1)}\right)+d\left(x^{(m+1)}, x^{(m+2)}+\cdots+d\left(x^{(n-1)}, x^{(n)}\right)\right. \\
& \preceq k^{m} d\left({ }^{(0)}, x^{(1)}\right)+k^{m+1} d\left(x^{(0)}, x^{(1)}\right)+\cdots+k^{n-1} d\left(x^{(0)}, x^{(1)}\right) \\
& =\left(k^{m}+k^{m+1}+\cdots+k^{n-1}\right) d\left(x^{(0)}, x^{(1)}\right) \\
& \preceq \frac{k^{m}}{1-k} d\left(x^{(0)}, x^{(1)}\right) .
\end{aligned}
$$

Karena

$P$ cone normal, maka $\left\|d\left(x^{(n)}, x^{(m)}\right)\right\| \leq \frac{k^{n}}{1-k} K\left\|d\left(x^{(0)}, x^{(1)}\right)\right\|$. Karena $k<1$, akibatnya $d\left(x^{(n)}, x^{(m)}\right) \rightarrow \overline{0}$. Berdasarkan Lema 3.8 barisan $\left(x^{(n)}\right)$ merupakan barisan Cauchy pada ruang metrik cone $(X, d)$. Karena $(X, d)$ lengkap, berdasarkan 
Definisi $3.10 x^{(n)}$ konvergen ke suatu $x^{*} \in X$. Berdasarkan Definisi 2.17 dan Definisi 2.21 diperoleh:

$$
\begin{aligned}
d\left(T x^{*}, x^{*}\right) & \preceq d\left(T x^{*}, T x^{(n)}\right)+d\left(T x^{(n)}, x^{*}\right) \\
& =d\left(T x^{(n)}, T x^{*}\right)+d\left(T x^{(n)}, x^{*}\right) \\
& \preceq k d\left(x^{(n)}, x^{*}\right)+d\left(x^{(n+1)}, x^{*}\right) .
\end{aligned}
$$

Karena $P$ merupakan cone normal, berdasarkan Definisi 2.16 berlaku $\left\|d\left(T x^{*}, x^{*}\right)\right\| \leq K\left\|k d\left(x^{(n)}, x^{*}\right)+d\left(x^{(n+1)}, x^{*}\right)\right\|$. Karena $\left(x^{(n)}\right)$ konvergen ke $x^{*}$, diperoleh $\left\|d\left(T x^{*}, x^{*}\right)\right\|=0$. Dari Definisi 2.1 dan Definisi 2.17 haruslah $d\left(T x^{*}, x^{*}\right)=\overline{0}$ dan $T x^{*}=x^{*}$, maka $x^{*}$ merupakan titik tetap dari pemetaan $T$. Selanjutnya akan ditunjukkan bahwa titik tetap pemetaan $T$ Tunggal. Misalkan terdapat titik tetap lain dari $T$ yaitu $y^{*}$. Akan ditunjukkan bahwa $y^{*}=x^{*}$. Karena $y^{*}$ titik tetap $T$ maka $T y^{*}=y^{*}$, sehingga $d\left(x^{*}, y^{*}\right)=d\left(T x^{*}, T y^{*}\right)$. Karena $T$ kontraktif maka $d\left(x^{*}, y^{*}\right)=d\left(T x^{*}, T y^{*}\right) \preceq k d\left(x^{*}, y^{*}\right)$. Karena $k<1$ maka haruslah $d\left(x^{*}, y^{*}\right)=\overline{0}$, maka haruslah $x^{*}=y^{*}$. Terbukti titik tetap pemetaan $T$ tunggal.

Akibat Teorema 3.12, pemetaan kontraktif pada ruang metrik cone $(X, d)$ memiliki titik tetap tunggal pada lingkungan- $c$ dari titik $x_{0} \in X$.

Akibat 3.13. [7] Misalkan $(X, d)$ ruang metrik cone lengkap dan $P$ cone normal. Didefinisikan himpunan $B\left(x^{(0)}, c\right)=\left\{x \in X \mid d\left(x^{(0)}, x\right) \preceq c\right\}$ untuk suatu $c \in E$ dimana $\overline{0} \ll c$ dan $x^{(0)} \in X$. Misalkan $T: X \rightarrow X$ suatu pemetaan kontraktif dimana untuk setiap $x, y \in B\left(x^{(0)}, c\right)$ berlaku $d(T x, T y) \preceq k d(x, y)$ dengan $k \in[0,1)$ dan $d\left(x^{(0)}, T x^{(0)}\right) \preceq(1-k)$ c. Maka titik tetap pemetaan $T$ berada di $B\left(x^{(0)}, c\right)$.

Bukti. Misalkan $\left(x^{n}\right)$ adalah barisan pada $X$ yang didefinisikan oleh:

$$
x^{(1)}=T x^{(0)}, x^{(2)}=T x^{(1)}=T^{2} x^{(0)}, \cdots, x^{(n)}=T x^{(n-1)}=\cdots=T^{n} x^{(0)} .
$$

Berdasarkan pembuktian dari Teorema 3.12 diketahui bahwa $\left(x^{(n)}\right)$ adalah barisan Cauchy dan untuk setiap $n, m \in \mathbb{N}$ dimana $n>m$ berlaku $d\left(x^{(m)}, x^{(n)}\right) \preceq \frac{k^{m}}{1-k} d\left(x^{(0)}, x^{(1)}\right)$. Misalkan $m=0$, maka untuk setiap $n>0$ berlaku:

$$
\begin{aligned}
d\left(x^{(0)}, x^{(n)}\right) & \preceq \frac{1}{1-k} d\left(x^{(0)}, x^{(1)}\right) \\
& =\frac{1}{1-k} d\left(x^{(0)}, T x^{(0)}\right) \\
& \preceq \frac{1}{1-k}(1-k)(c) \preceq c .
\end{aligned}
$$

Dengan kata lain, untuk setiap $n \in \mathbb{N}$ berlaku $x^{(n)} \in B\left(x^{(0)}, c\right)$. Karena $\left(x^{(n)}\right)$ adalah barisan Cauchy dan $(X, d)$ adalah ruang metrik cone lengkap, maka $\left(x^{(n)}\right)$ konvergen ke suatu $x \in X$. Dari Teorema 3.12 diketahui bahwa $x$ adalah titik tetap pemetaan $T$. Selanjutnya akan ditunjukkan bahwa $x \in B\left(x^{(0)}, c\right)$. Perhatikan bahwa 


$$
\begin{aligned}
d\left(x^{(0)}, x\right) & \preceq d\left(x^{(0)}, x^{(n)}\right)+d\left(x^{(n)}, x\right) \\
& \preceq c+d\left(x^{(n)}, x\right) .
\end{aligned}
$$

Karena $x^{(n)}$ konvergen ke $x$ akibatnya $d\left(x^{(0)}, x\right) \preceq c$. terbukti $x \in B\left(x^{(0)}, c\right)$.

\section{Kesimpulan}

Konsep kekonvergenan barisan pada ruang metrik dapat diterapkan pada ruang metrik cone. dimana suatu barisan pada ruang metrik cone $(X, d)$ dikatakan konvergen ke suatu $x \in X$ jika dan hanya jika jarak antara barisan tersebut dengan $x$ konvergen ke $\overline{0}$. Kemudian, pemetaan kontraktif $T$ pada ruang metrik cone lengkap $(X, d)$ memiliki titik tetap tunggal di $X$.

\section{Ucapan Terima kasih}

Penulis mengucapkan terima kasih kepada Bapak Syafrizal Sy, Bapak Jenizon dan Bapak Mahdhivan Syafwan yang telah memberikan masukan dan saran sehingga artikel ini dapat diselesaikan dengan baik.

\section{Daftar Pustaka}

[1] Bartle, Robert G. Donald R. Sherbert. 2011. Introduction to Real Analysis 4th Edition. John Wiley and Sons, New York

[2] Fernandez, Jerolina.et. al. 2017. The A-Cone Metric Space Over Banach Algebra With Applications. Congent Mathematics 4 : 1-20

[3] Karapinar, E. 2009. Fixed Point Theorems in Cone Banach Spaces. Department of Mathematics, Atilim University:1-9

[4] Kreyszig, E. 1978. Introductional Functional Analysis with Application. John Wiley and Sons, New York

[5] Long, Huang G. Zhang Xian. 2007. Cone metric spaces and fixed point theorems of contractive mappings. Science Direct,332: 1468-1476.

[6] Mukhtar Gozali, Sumanang. 2010. Pengantar Analisis Fungsional. Universitas Pendidikan Indonesia : Bandung

[7] Nazam, Muhammad. Anam Arif. Etc. 2020. Fixed Point Problem in Cone Rectangular Metric Space with Application. Hindawi: 1-10. 